\title{
Direitos reprodutivos de mulheres e homens face à nova legislação brasileira sobre esterilização voluntária
}

\author{
Reproductive rights of women and men \\ in light of new legislation on voluntary \\ sterilization in Brazil
}

Elza Berquó 1,2

Suzana Cavenaghi 2

\footnotetext{
${ }^{1}$ Comissão Nacional de População e Desenvolvimento.

2 Programa de Saúde Reprodutiva e Sexualidade, Núcleo de Estudos de População, Universidade Estadual de Campinas. C. P. 6166, Campinas, SP 12081-970, Brasil. berquo@nepo.unicamp.br cavenagh@nepo.unicamp.br
}

\begin{abstract}
This paper aims to analyze the impacts and possible changes that the implementation of a new Brazilian family planning law has on reproductive practices, especially voluntary sterilization, and to determine whether men's and women's reproductive rights are being respected. The methodological approach is based on a six-month follow-up survey taken monthly, applied to a sample of 159 individuals in six contextually different State capitals. Besides verifying whether the health sector is complying with the criteria set by the law, we analyze the waiting time between the request for sterilization and the surgery itself, utilizing survival analysis. We also conduct interviews with health professionals, shedding light on the procedures adopted in the practice of sterilization. For various reasons, the law has produced little change in the usual practice of sterilization, besides failing to satisfy individual reproductive rights.
\end{abstract}

Key words Reproductive Health; Voluntary Sterilization; Legislation; Family Planning

Resumo O objetivo deste trabalho é analisar os impactos e as possíveis mudanças que a implementação da nova legislação sobre planejamento familiar teve nas práticas reprodutivas, especialmente na esterilização voluntária, e observar se os diretos reprodutivos de mulheres e homens têm sido satisfeitos. A abordagem metodológica é baseada em uma pesquisa follow-up, aplicada a uma amostra de 159 individuos durante seis meses e em seis diferentes capitais de estado. Além de verificar se os critérios estabelecidos na lei estavam sendo seguidos pelo setor público de saúde, nós analisamos o tempo de espera entre a solicitação pela esterilização e a realização da cirurgia, utilizando análise de sobrevivência. Adicionalmente, foram realizadas entrevistas com profissionais de saúde, as quais são muito elucidativas dos procedimentos adotados na prática da esterilização. Os resultados mostram que, por diferentes motivos, a lei mudou pouco a prática usual da esterilização e ainda não satisfaz os direitos reprodutivos de mulheres $e$ homens no Brasil.

Palavras-chave Saúde Reprodutiva; Esterilização Voluntária; Legislação; Planejamento Familiar 


\section{Introdução}

A esterilização feminina voluntária tem sido há muito tempo uma prática comum no setor privado da saúde no Brasil como meio de controle da fecundidade. No sistema público, entretanto, a esterilização não era permitida, não havendo, portanto, autorização para pagamento das cirurgias de laqueadura tubária. No entanto, é de notório e amplo conhecimento que várias cirurgias eram de fato realizadas durante partos por cesariana (Barros et al., 1991; Berquó, 1993; Faúndes \& Cecatti, 1991, 1993; Hopkins, 1998; Souza 2001) e, fora do parto, muitas eram registradas como outros procedimentos médicos (Caetano, 2000).

Como resultado destas práticas, a esterilização feminina se tornou o método mais utilizado dentre todos aqueles disponíveis para anticoncepção. De acordo com a Pesquisa Nacional sobre Demografia e Saúde (PNDS) de 1996, a esterilização feminina consistia de $52,0 \%$ de todos os métodos contraceptivos utilizados, seguida em segundo lugar e com considerável distância, pela pílula, usada por $27,0 \%$ da população feminina. A esterilização masculina, no relato dos homens, por outro lado, era menos praticada $(2,4 \%)$ do que métodos tradicionais como a abstinência periódica $(4,0 \%)$ e o coito interrompido (4,0\%) (BEMFAM/Macro International, 1997).

A despeito da inexistência de qualquer lei específica que proibisse a realização da esterilização voluntária, a sua prática não era permitida com base no Código Penal Brasileiro de 1940, Artigo 29, Parágrafo 2.III, o qual diz que qualquer lesão corporal de natureza grave, resultando em debilidade permanente de membro, sentido ou função do corpo é considerada como crime. A esterilização voluntária era, portanto, interpretada como ofensa criminal, desde que resulta em perda ou incapacidade da função reprodutiva e sua prática carrega consigo uma penalidade de um a oito anos de reclusão.

O Código de Ética Médica (por meio da Resolução 1.154 - CFM, 1984) proibia a esterilização voluntária até 1988; no entanto, casos excepcionais eram considerados quando existia indicação médica precisa, atestada por dois médicos ouvidos em conferência. Em 1988, o Código de Médica Ética revoga a decisão anterior e explicitamente exige que os médicos sigam as leis específicas, afirmando: "é vedado ao médico ... descumprir legislação específica nos casos de transplantes de órgãos ou tecidos, esterilização, fecundação artificial e abortamento" (Artigo 43).
A ilegalidade associada à sua realização e a alta demanda pela esterilização explicam, em grande parte, porque a laqueadura tubária é tão freqüentemente praticada durante a cesariana no setor privado. Este fato é muitas vezes citado como uma das causas da extrema alta taxa de partos cirúrgicos realizados no Brasil e a alta e direta associação entre partos por cesariana e esterilização feminina. De acordo com a PNDS de 1996, mais de 50,0\% de todas as esterilizações ocorreram durante um nascimento por cesariana. Nas regiões mais desenvolvidas do país estas estimativas chegam a $70,0 \%$, indicando um abuso deste procedimento como meio de esterilização.

Assim como a esterilização voluntária não era legalizada, também o planejamento familiar no Brasil não era regulamentado e somente recentemente a legislação em saúde e direitos reprodutivos foi aprovada. Em 1997, a esterilização voluntária feminina e masculina foi regulamentada pela Portaria 144 do Ministério da Saúde (MS), de acordo com a Lei 9.263, de 1996, dentro de um escopo maior sobre a legislação do planejamento familiar (Brasil, 1997a, 1997b). O artigo principal da lei (Art. 10), com relação à esterilização diz que: "Somente é permitida a esterilização voluntária nas seguintes situações: I-em homens e mulheres com capacidade civil plena e maiores de 25 anos de idade ou, pelo menos, com dois filhos vivos, desde que observado o prazo mínimo de sessenta dias entre a manifestação da vontade e o ato cirúrgico, período no qual será propiciado à pessoa interessada acesso ao serviço de regulação da fecundidade, incluindo aconselhamento por equipe multidisciplinar, visando desencorajar a esterilização precoce".

A Portaria 144 criou um código de procedimento cirúrgico que permite que o sistema público de saúde pague pela realização da laqueadura tubária e regulamentou o código para vasectomia. Um aspecto importante da implementação da lei no Sistema Único de Saúde (SUS) é que esta mesma Portaria especifica as regras de credenciamento dos hospitais para realizarem a esterilização voluntária pelo SUS e disponibiliza o formulário correspondente ao credenciamento. Adicionalmente, fornece o formulário individual de notificação ao SUS das cirurgias de laqueadura tubária e vasectomia, o qual inclui dados sobre o endereço do paciente, sexo, data de nascimento, número de filhos e escolaridade. Esta portaria permaneceu em vigor por mais de um ano e, durante este período, poucos hospitais no país foram credenciados. Como conseqüência, poucas esterilizações foram registradas no SUS neste tempo. 
Em fevereiro de 1999, houve uma mudança significativa na regulamentação da lei, por meio da Portaria 048 de 11 de fevereiro de 1999. A maior modificação apresentada nesta portaria foi a proibição da realização da laqueadura tubária durante o período do parto ou aborto e até 42 dias depois destes, exceto em casos de cesarianas sucessivas anteriores e casos onde a exposição a outro ato cirúrgico representasse risco de vida para a mulher. Assim, são criados mais quatro novos códigos de procedimentos cirúrgicos pagos pelo SUS para realização de “cesariana com laqueadura tubária em pacientes com cesarianas sucessivas anteriores”, sem muitos esclarecimentos sobre as diferenças entre eles, aparentemente para grupos de risco distintos: (1) risco de vida; (2) risco de vida com atendimento ao recém-nascido na sala de parto; (3) risco de vida em hospitais amigos da criança e (4) em gestante de alto risco. Vale notar que nenhuma das Portarias de regulamentação da lei especifica o número de cesarianas sucessivas a partir da qual a esterilização feminina seria permitida no momento do parto, mas é de comum conhecimento que três cesarianas sucessivas é usada como parâmetro, ou seja, duas cesarianas sucessivas anteriores viabilizam a realização da laqueadura durante um terceiro parto por cesariana.

De acordo com os dados dos registros administrativos de autorização de procedimentos de internação hospitalar (AIH-DATASUS), há um incremento no número de esterilizações femininas registradas no Brasil (de $293 \mathrm{em}$ 1998 para 15.370 em 2001). Este incremento aconteceu em todo o país, principalmente na Região Sudeste. O número de vasectomias, apesar de mostrar valores bem abaixo da laqueadura, também mostrou um crescimento de 1999 a 2001, passando de 324 a 3.142 (DATASUS, 2001).

\section{Objetivo}

O objetivo geral do presente trabalho é verificar como está o atendimento, pelo sistema público de saúde, aos demandantes da laqueadura tubária e da vasectomia após a nova lei do planejamento familiar - no que se refere à esterilização voluntária.

Como objetivos específicos, o trabalho se propõe a: (1) Avaliar a observância dos critérios estipulados na lei nos demandantes por esterilização; (2) Investigar como os profissionais de saúde se posicionam quanto aos critérios da lei e (3) Estimar o tempo de espera entre a solicitação pela esterilização e sua efetivação.

\section{Metodologia}

\section{Delineamento da pesquisa}

A pesquisa conduzida com a finalidade de buscar responder aos objetivos propostos, foi realizada em Palmas, Recife, Cuiabá, Belo Horizonte, São Paulo e Curitiba. No intuito de incluir no estudo as cinco grandes regiões do país, estas cidades foram selecionadas por serem as capitais de estados com alta prevalência de esterilização feminina. Em nível local contou-se com a colaboração de organizações governamentais e não-governamentais.

Em cada capital foram acompanhados 15 mulheres e 15 homens demandantes de esterilização em um estabelecimento público de saúde ou conveniado com o SUS, desde o primeiro momento da demanda e com contatos mensais durante seis meses. Dois tipos de estabelecimentos de saúde serviram como portas de entrada para os demandantes. Um tipo é referido aqui como serviço ambulatorial de hospitais, definidos como estabelecimentos fisicamente anexados a um hospital, mas gerenciado independentemente. O segundo é o serviço ambulatorial de centro de saúde. Uma característica em comum destes dois tipos de estabelecimentos é que eles não realizam cirurgias maiores, portanto, as mulheres devem ser referenciadas a um hospital para realizar a laqueadura tubária. A maior diferença entre estes centros de saúde é que os serviços ambulatoriais de hospitais usualmente encaminham as usuárias a serem laqueadas para o hospital no qual estão anexados, possivelmente diminuindo as dificuldades burocráticas e melhorando o acesso à cirurgia. A esterilização masculina, por outro lado, pode ser realizada em qualquer um destes tipos de centros de saúde, pois tem a característica de ser um procedimento ambulatorial de relativa simplicidade.

Os centros de saúde foram escolhidos aleatoriamente, em um total de seis em cada cidade, distribuídos entre os dois tipos de ambulatórios descritos acima, de acordo com a disponibilidade destes no município. Foram selecionados e entrevistados as três primeiras mulheres e três primeiros homens que solicitaram a esterilização nestes centros de saúde após o início da pesquisa, totalizando 15 mulheres e 15 homens. Depois do contato inicial, os entrevistados foram contatados mensalmente (com entrevistas pessoalmente ou por telefone) pelos seis meses seguintes, para verificar se a esterilização tinha sido realizada ou negada. Quando uma destas situações ocorreu, ou no final dos seis meses, uma entrevista final foi agendada. 
Além do acompanhamento dos usuários, várias entrevistas com os profissionais de saúde foram realizadas, utilizando questionários estruturados. Depois de completar a cota dos usuários, o coordenador ou gerente do centro de saúde foi entrevistado, totalizando trinta entrevistas. Adicionalmente, cinco entrevistas com os gerentes de hospitais foram conduzidas em cada município de estudo, exceto em Palmas, onde somente existem três hospitais. Finalmente, os coordenadores municipais e estaduais responsáveis pela saúde reprodutiva, em cada município, foram entrevistados, totalizando 12 entrevistas. Devido a perdas durante o acompanhamento com os usuários ou falta de preenchimento das cotas em alguns locais, o tamanho final da amostra de usuários foi de 71 homens e 88 mulheres. Já para os profissionais de saúde, foram entrevistados 31 gerentes de ambulatório, 28 gerentes de hospitais e 12 coordenadores municipais ou estaduais de saúde reprodutiva.

\section{Métodos de análise dos dados}

A abordagem metodológica utilizada para detectar diferenças nas chances que certos grupos de usuários podem ter para conseguir fazer a esterilização pelo SUS, consiste principalmente de análise de distribuições bivariadas para variáveis selecionadas, devido ao pequeno tamanho da amostra. Investiga-se também, se a combinação para os principais critérios especificados na lei, idade e número de filhos, são ou não uma restrição associada à realização da esterilização.

O tempo de espera desde a solicitação até a realização da cirurgia foi analisado com método de análise de sobrevivência, baseado na abordagem de tábua de vida, para detectar possíveis características que pudessem diferenciar a probabilidade de obter esterilização no SUS. Casos censurados (0) foram definidos como aqueles em que os indivíduos "falharam" no seu intento de obter a esterilização após o período de observação (seis meses), ou que saíram do estudo pelos mais diversos motivos. Os casos (1) são considerados aqueles onde os indivíduos foram esterilizados dentro do período do acompanhamento. Neste caso, a probabilidade de "sobrevivência" é assumida como a probabilidade de não obter esterilização, e falha é associada com a probabilidade de obter a esterilização. O modelo foi estimado utilizando-se o procedimento lifetest do programa Statistical Analysis System (SAS - 1999-2000).

Para as entrevistas com os profissionais de saúde, neste trabalho analisam-se somente aque- les aspectos relacionados com o conhecimento dos critérios definidos na lei com relação à esterilização feminina e masculina. Finalmente, com o objetivo de obter casos suficientes para a análise, os dados são agregados, sem diferenciar as tendências entre as cidades.

\section{Resultados}

Regulamentação da esterilização voluntária nos locais da pesquisa

Todos os municípios onde a pesquisa foi realizada faziam parte do SUS, mas em alguns deles o sistema ainda não estava totalmente implementado em 2000, quando o trabalho foi levado a campo. O Município de São Paulo é um exemplo destes: na época da pesquisa tinha dois sistemas de saúde operando na cidade, um em nível estadual e outro em nível municipal. A situação é ainda mais heterogênea entre as várias cidades em termos de organização dos cuidados com a saúde reprodutiva e, especialmente, com relação ao estágio de credenciamento das unidades de saúde que realizam a esterilização voluntária.

Dentre as seis cidades estudadas, as mais organizadas, em termos de cuidados com a saúde reprodutiva e disponibilidade de serviços de planejamento familiar são, Curitiba, Belo Horizonte e São Paulo, onde os programas de planejamento familiar estão operando desde 1994 . Nas duas primeiras cidades e no sistema municipal de saúde em São Paulo existe regulamentação municipal específica para a prática de esterilização no SUS. Em Recife e Cuiabá, a organização do sistema de cuidados com a saúde reprodutiva é mais recente e ainda não está totalmente implementado em todas as unidades básicas de saúde, portanto, não tem nenhuma regulamentação específica sobre a esterilização. No começo da pesquisa, o programa de saúde reprodutiva em Palmas ainda não estava implementado, apesar de estar sendo planejado desde 1997, mas durante a realização da pesquisa de campo o programa foi finalmente implementado.

Nos locais onde existe regulamentação específica sobre a esterilização voluntária, esta não está perfeitamente de acordo com as normas e critérios definidos na lei. Na verdade, os critérios usados restringem mais o acesso à esterilização feminina e masculina no sistema de saúde pública do que a própria lei. A interpretação incorreta da lei mais comumente encontrada é a combinação dos critérios sobre idade e número de filhos, onde o critério 25 anos "ou" 
dois filhos é substituído por 25 anos e dois filhos. Isto em geral ocorre porque os médicos explicitamente dizem que as mulheres (nunca os homens) muito jovens estão sendo esterilizadas e as taxas de arrependimento são muito altas. No entanto, a literatura sobre a questão não encontra casos de arrependimento suficientes para comprovar este argumento (Hardy et al., 1996; Vieira \& Ford, 1996). Outra distorção da lei usualmente exercida é o aumento da idade e número de filhos mínimos exigidos pelas regulamentações municipais. Adicionalmente, vale ressaltar que alguns critérios que não são incluídos na lei são muitas vezes mencionados e utilizados na prática, tais como condições sócio-econômicas e estabilidade conjugal.

O protocolo de planejamento familiar em Curitiba explicita que a laqueadura tubária é permitida para mulheres com pelo menos 25 anos de idade e com dois filhos vivos. A esterilização para os homens tem critérios ainda mais restritivos que para as mulheres, pois a vasectomia somente é permitida em homens com pelo menos trinta anos de idade, com três filhos e sem doença genital conhecida. De acordo com alguns profissionais da saúde entrevistados, a base para esta restrição é que o sistema deve estabelecer prioridades para selecionar os indivíduos para autorizar a esterilização, pois a quantidade de cirurgias realizadas mensalmente é definida por cotas, as quais são insuficientes para atender a alta demanda.

Em São Paulo, apesar das regulamentações locais não conterem explicitamente interpretações errôneas da lei, elas estão implícitas nas normas existentes. Os serviços de saúde municipais em São Paulo usam um procedimento de pontuação para selecionar e dar prioridades para a aprovação das solicitações pela esterilização. Indivíduos abaixo de trinta anos e com menos do que três filhos não conseguem atingir a pontuação mínima, cinco pontos, necessária para a aprovação do pedido. Os serviços estaduais não seguem o mesmo sistema de pontuação e não há um protocolo escrito a ser seguido, mas as regras de trinta anos de idade e ter três filhos ou mais são utilizadas nos hospitais estaduais, de acordo com as informações obtidas nas entrevistas com os profissionais de saúde destes estabelecimentos.

Uma lei municipal sobre a esterilização voluntária prevalece em Belo Horizonte desde 1994, a qual é mais restrita que a lei federal com relação ao critério de idade mínima. Homens e mulheres devem ter pelo menos trinta anos de idade para conseguirem autorização para seus pedidos de esterilização. A maior dificuldade em Belo Horizonte é a escassa disponibilidade de leitos hospitalares que são necessários antes da marcação da cirurgia.

Como mencionado acima, Recife, Cuiabá e Palmas não têm regulamentação municipal para a esterilização voluntária, mas os critérios seguidos para realizar a cirurgia, pelo menos no discurso dos profissionais de saúde, são os mesmos explicitados na lei federal. No entanto, algumas vezes estes são mal interpretados e alguns critérios que não existem são mencionados, como nos outros municípios, como é o caso das condições sócio-econômicas e estabilidade conjugal. Finalmente, é importante mencionar que durante o trabalho de campo em Palmas, o secretário da saúde proibiu a prática da esterilização voluntária paga pelo SUS, alegando que os candidatos a cargos públicos poderiam trocar esterilizações por votos.

\section{Características da amostra}

Como pode ser visto na Tabela 1, das mulheres e dos homens que demandaram a esterilização cirúrgica, $71,9 \%$ e 70,4\%, respectivamente, o fizeram usando ambulatórios de centros de saúde do SUS como porta de entrada, cabendo aos ambulatórios de hospitais o restante da demanda.

A amostra de mulheres esteve composta de $53,4 \%$ de negras, (ou seja pretas e pardas), de $55,7 \%$ na faixa de 26 a 34 anos, de $77,3 \%$ de casadas ou unidas, $72,7 \%$ tiveram três ou mais filhos nascidos vivos, $62,9 \%$ se declararam católicas e 54,5\% não chegaram a completar o ensino fundamental.

Quanto aos homens, a maior parte também era negra $(52,1 \%)$, porém mais velhos, isto é, $52,2 \%$ na faixa de 35 ou mais anos de idade, quase todos casados ou unidos (95,6\%), 57,7\% com três ou mais filhos, $66,2 \%$ com no mínimo o ensino fundamental completo e $56,3 \%$ com filiação religiosa católica. Vale salientar que quanto à renda familiar per capita, os homens encontravam-se em situação melhor do que as mulheres, ou seja, $74,6 \%$ na faixa mais elevada, a qual foi atingida por apenas $32,9 \%$ das mulheres.

Analisando a composição por idade e número de filhos nascidos vivos, das amostras de mulheres e de homens que demandaram a esterilização cirúrgica, pode-se observar algumas diferenças. Enquanto mulheres de 26 a 34 anos com dois ou mais filhos predominam na amostra feminina, ou seja, correspondem a $62,5 \%$, no conjunto dos homens, o segmento mais freqüente, correspondendo a $46,5 \%$ do total, tem 35 ou mais anos de idade e dois ou mais filhos. 
Tabela 1

Composição da amostra de pessoas que demandaram esterilização, segundo variáveis sócio-demográficas, por sexo.

\begin{tabular}{|c|c|c|}
\hline Variáveis & $\begin{array}{l}\text { Mulheres } \\
\text { (88) }\end{array}$ & $\begin{array}{l}\text { Homens } \\
\text { (71) }\end{array}$ \\
\hline \multicolumn{3}{|l|}{ Idade (em anos) } \\
\hline - 24 & 15,9 & 4,2 \\
\hline $25-34$ & 63,6 & 43,76 \\
\hline $35+$ & 20,5 & 52,1 \\
\hline Total & 100,0 & 100,0 \\
\hline \multicolumn{3}{|l|}{ Raça/Cor } \\
\hline Branca & 37,5 & 45,1 \\
\hline Negra & 53,4 & 50,7 \\
\hline O utra & 9,1 & 4,2 \\
\hline Total & 100,0 & 100,0 \\
\hline \multicolumn{3}{|l|}{ Anos de estudo } \\
\hline $0-3$ & 12,5 & 7,0 \\
\hline $4-7$ & 42,0 & 26,8 \\
\hline $8+$ & 45,5 & 66,2 \\
\hline Total & 100,0 & 100,0 \\
\hline \multicolumn{3}{|l|}{ Status conjugal } \\
\hline Casado & 77,3 & 95,8 \\
\hline Não casado & 22,7 & 4,2 \\
\hline Total & 100,0 & 100,0 \\
\hline \multicolumn{3}{|c|}{$\begin{array}{l}\text { Renda familiar per capita } \\
\text { (em Reais) }\end{array}$} \\
\hline - 40 & 39,8 & 9,9 \\
\hline $41-80$ & 27,3 & 15,5 \\
\hline $81+$ & 32,9 & 74,6 \\
\hline Total & 100,0 & 100,0 \\
\hline \multicolumn{3}{|l|}{ Religião } \\
\hline Católica & 62,5 & 56,3 \\
\hline O utras & 37,5 & 43,7 \\
\hline Total & 100,0 & 100,0 \\
\hline \multicolumn{3}{|c|}{ Número de nascidos vivos } \\
\hline - 1 & 2,3 & 9,9 \\
\hline $2+$ & 97,7 & 90,1 \\
\hline Total & 100,0 & 100,0 \\
\hline \multicolumn{3}{|c|}{ Tipo de serviço de saúde } \\
\hline Serviço ambulatorial & 71,9 & 70,4 \\
\hline $\begin{array}{l}\text { Serviço ambulatorial } \\
\text { de hospital }\end{array}$ & 28,1 & 29,6 \\
\hline Total & 100,0 & 100,0 \\
\hline
\end{tabular}

Fonte: Estudo multicêntrico sobre o impacto da nova legislação sobre o planejamento familiar, 2000
Outra informação que foi também levantada na primeira entrevista com as demandantes referiu-se ao uso atual de métodos anticoncepcionais. Quase um quarto do total de mulheres não estava usando nenhum meio para evitar uma concepção. Das usuárias, a pílula respondeu por $30,7 \%$, seguida do preservativo masculino pelos seus parceiros, $23,9 \%$, vindo os injetáveis em terceiro lugar, 10,2\%.

Dentre os homens, a proporção de não uso foi mais elevada, ou seja, $36,6 \%$, alcançando $39,5 \%$ caso se inclua dois casos em que por estar a parceira laqueada, eles não usavam nenhum método. Dos usuários, o preservativo se destaca com $32,4 \%$, seguido da pílula pelas suas parceiras, com $23,9 \%$. Vale registrar ainda que $98,1 \%$ dos entrevistados sabiam que a laqueadura tubária pode ser irreversível.

\section{Demandas atendidas}

Após um seguimento de aproximadamente seis meses, apenas $25,8 \%$ das mulheres que demandaram esterilização tiveram sucesso. Dentre os homens, $31,0 \%$ conseguiram a vasectomia (Tabela 2).

Estas proporções foram mais elevadas quando as demandas no SUS foram feitas via serviços de ambulatórios de hospitais, correspondendo a $36,0 \%$ para as mulheres e $38,1 \%$ para os homens. Uma razão para esta diferença pode ser devida a uma menor burocracia quando a porta de entrada for via serviços ambulatoriais de hospitais.

Nota-se também que para as mulheres, as chances de conseguir uma esterilização não dependem da idade, cor, anos de estudo, renda, situação conjugal ou religião. Para os homens, entretanto, a situação é bem diferente. As chances de conseguir uma vasectomia são maiores para os homens brancos, casados, mais velhos, com maior escolaridade e com maior renda.

Quando se combinam os dois critérios de idade e número de filhos nascidos vivos, declarados no momento da demanda por esterilização, observa-se, em primeiro lugar, não ter havido demandas de pessoas com menos de 25 anos e apenas um filho, possivelmente em atendimento à lei. Em segundo lugar, as demandas provieram quase todas de pessoas com dois ou mais filhos, correspondendo a $97,7 \%$ para as mulheres e a $90,1 \%$ para os homens. Em terceiro lugar, $84,1 \%$ das demandas femininas e $95,8 \%$ das masculinas, situaram-se na faixa etária de 25 anos ou mais. Finalmente, a maior chance de esterilização ocorreu para mulheres com idades entre 25 e 34 anos e para homens na faixa de 35 anos ou mais. 
Proporção de mulheres e homens esterilizados, segundo variáveis sócio-demográficas.

\begin{tabular}{|c|c|c|}
\hline \multirow[t]{2}{*}{ Variáveis } & \multicolumn{2}{|c|}{ Esterilizados (\%) } \\
\hline & $\begin{array}{l}\text { Mulheres } \\
(88)\end{array}$ & $\begin{array}{l}\text { Homens } \\
\text { (71) }\end{array}$ \\
\hline \multicolumn{3}{|l|}{ Idade (em anos) } \\
\hline - 24 & 21,4 & 0,0 \\
\hline $25-34$ & 26,8 & 22,6 \\
\hline $35+$ & 27,8 & 40,5 \\
\hline \multicolumn{3}{|l|}{ Raça/Cor } \\
\hline Branca & 21,2 & 46,9 \\
\hline Não Branca & 22,9 & 21,2 \\
\hline \multicolumn{3}{|l|}{ Anos de estudo } \\
\hline $0-3$ & 27,3 & 20,0 \\
\hline $4-7$ & 24,3 & 15,8 \\
\hline $8+$ & 26,8 & 38,3 \\
\hline \multicolumn{3}{|l|}{ Status marital } \\
\hline Casados & 26,5 & 32,3 \\
\hline Não casados & 25,0 & 0,0 \\
\hline \multicolumn{3}{|l|}{$\begin{array}{l}\text { Renda per capita } \\
\text { (em Reais) }\end{array}$} \\
\hline - 40 & 25,7 & 0,0 \\
\hline $41-80$ & 29,0 & 27,3 \\
\hline $81+$ & 24,0 & 35,8 \\
\hline \multicolumn{3}{|l|}{ Religião } \\
\hline Católica & 25,0 & 32,5 \\
\hline Outra & 27,3 & 29,0 \\
\hline \multicolumn{3}{|c|}{ Número de nascidos vivos } \\
\hline - 1 & - & 14,3 \\
\hline $2+$ & 25,6 & 32,8 \\
\hline \multicolumn{3}{|c|}{ Tipo de serviço de saúde } \\
\hline Serviço ambulatorial & 22,2 & 28,0 \\
\hline $\begin{array}{l}\text { Serviço ambulatorial } \\
\text { de hospital }\end{array}$ & 36,0 & 38,1 \\
\hline Total & 25,8 & 31,0 \\
\hline
\end{tabular}

\section{Aconselhamento}

Conforme estabelece o parágrafo único do Artigo 14 da Lei 9.263 (Brasil, 1997a), "só podem ser autorizadas a realizar esterilização cirúrgica as instituições que ofereçam todas as opções de meios e métodos de contracepção reversíveis". Neste sentido, aos homens e mulheres que demandaram esterilização cirúrgica, foi perguntado se passaram por sessões de aconselhamento, ou seja, se receberam orientações sobre todos os tipos de métodos para evitar filhos, antes da decisão definitiva de por fim à vida reprodutiva. Os resultados mostram que $73,0 \%$ das mulheres e $70,4 \%$ dos homens responderam que sim.

Estes achados podem estar refletindo o fato de que a grande maioria $(97,0 \%)$ dos diretores de hospital e de ambulatório - portas de entrada do SUS dos demandantes da esterilização cirúrgica deste estudo - manifestou-se favorável a esta exigência da lei. Vale destacar, ainda, que não diferiram estatisticamente, ao nível de significância de $5,0 \%$, as proporções de esterilizados dentre os que receberam e os que não receberam o referido aconselhamento. De fato, para as mulheres estes percentuais foram iguais a $24,6 \%$ e $30,8 \%$, respectivamente. Para os homens, corresponderam, pela ordem, a $30,0 \%$ e $31,2 \%$.

Sexo seguro após a esterilização

Aos esterilizados foi perguntado como pretendiam fazer no futuro para ter sexo seguro no sentido da prevenção do HIV/AIDS. As respostas mostram estarem as mulheres mais atentas quanto ao uso do preservativo, ou seja, $43,5 \%$ o citaram, em contraste com os $31,8 \%$ dos homens que o mencionaram. Seis em cada dez dos vasectomizados deram respostas baseadas na fidelidade da companheira, sem expressar seu comportamento quanto ao sexo protegido, no caso de relações eventuais.

Direitos reprodutivos e o cumprimento da lei pelo SUS

As entrevistas realizadas junto a diretores de hospital e de ambulatórios sobre a adequação ou não dos critérios exigidos pela Lei 9.263 para a realização da esterilização voluntária, revelaram resultados diferenciados conforme os vários requisitos (Tabela 3). Para os diretores de hospital o critério da idade mínima foi considerado o mais inadequado, seguido do número mínimo de filhos nascidos vivos. Segundo eles, as pessoas deveriam ser mais velhas ou terem tido mais filhos. 
Porcentagem de inadequação manifestada por responsáveis pela saúde reprodutiva, em nível estadual e municipal e diretores de hospitais e de ambulatórios.

\begin{tabular}{lcccc}
\hline $\begin{array}{l}\text { Critérios exigidos pela Lei 9.263 para } \\
\text { a realização de esterilização voluntária }\end{array}$ & $\begin{array}{l}\text { Gestor } \\
\text { estadual }\end{array}$ & $\begin{array}{l}\text { Gestor } \\
\text { municipal }\end{array}$ & $\begin{array}{l}\text { Diretor de } \\
\text { hospital }\end{array}$ & $\begin{array}{l}\text { Diretor de } \\
\text { ambulatório }\end{array}$ \\
\hline 25 anos & 50,0 & 67,0 & 71,0 & 34,0 \\
Dois filhos vivos & 17,0 & 33,0 & 46,0 & 15,0 \\
Consentimento do cônjuge & 50,0 & 33,0 & 17,0 & 18,0 \\
Autorização judicial & 33,0 & 33,0 & 18,0 & 22,0 \\
Fora do parto/aborto e puerpério & 16,0 & 33,0 & 39,0 & 26,0 \\
Carência de 60 dias & 17,0 & 17,0 & 29,0 & 42,0 \\
Serviço de aconselhamento & 0,0 & 0,0 & 3,0 & 3,0 \\
Consentimento informado & 0,0 & 0,0 & 3,0 & 3,0 \\
Risco de vida da mãe e concepto & 0,0 & 0,0 & 3,0 & 3,0 \\
Número de casos & 6 & 6 & 28 & 31 \\
\hline
\end{tabular}

A carência de sessenta dias entre a demanda e seu atendimento foi considerada, por outro lado, como muito longa, principalmente para os diretores de ambulatórios. A objeção aos 25 anos como idade mínima foi também endossada por gestores estaduais e municipais de saúde.

Os motivos mais alegados por mulheres e homens para não terem sido esterilizados, após um tempo médio de espera de 6 meses, referem-se às dificuldades encontradas no SUS, apontadas por $54,8 \%$ das mulheres e $41,7 \%$ dos homens. Ainda aguardam no SUS outros 12,9\% e $20,8 \%$ de mulheres e homens, respectivamente. No decorrer do tempo de espera, $25,0 \%$ dos homens e $14,5 \%$ das mulheres desistiram da esterilização. Vale ainda ressaltar que $8,1 \%$ das mulheres engravidam durante o período.

De fato, a grande maioria encontrou dificuldades no SUS, proporção maior para as mulheres $(54,8 \%)$ do que para os homens $(41,7 \%)$. As dificuldades alegadas pelas mulheres incluem: difícil acesso para solicitação, ausência de médicos, má vontade, burocracia do SUS acarreta longo tempo de espera, SUS não respeita critério de idade ou número de filhos vivos, ser solteira, não ter quem assine, médico alega arrependimento, médico do SUS cobra extra pela cirurgia e médico não recomenda por motivo "médico" (pressão alta). Sendo que, as duas primeiras citações respondem por $76,4 \%$ das referidas dificuldades.

As razões para desistência apresentadas pelas mulheres foram: medo de arrependimento, decisão por colocar DIU, ser jovem, início da menopausa, marido não assina o consentimento, acidente durante a espera e fazer em hospital particular. Dentre os "outros motivos", in- clui-se não possuir carteira de identidade, não ter ainda registro de nascimento do último filho e separação.

Os homens que não conseguiram a vasectomia pelo SUS, assim expressaram seus motivos: burocracias do SUS, longas filas etc.; SUS não respeita critério de idade ou número de filhos vivos; médico alega arrependimento; SUS não faz de graça; médico não recomenda por problemas de saúde (colesterol elevado) e cirurgia foi suspensa no período. As duas primeiras queixas respondem por $80,0 \%$ das impossibilidades do atendimento pelo SUS.

Dentre as razões que levaram os homens a desistir da vasectomia, destacam-se: arrependimento, mulher fez laqueadura, mulher usa outro método, era jovem, perdeu a data marcada, problemas de saúde e idade elevada.

\section{O tempo de espera para esterilização}

Modelos de tábua de vida do tempo de espera para a realização da esterilização foram ajustados para todas as variáveis mostradas na Tabela 1. A maioria dos modelos mostrou que não existem diferenças estatisticamente significantes no tempo de espera para obter a esterilização, quando comparadas as categorias destas variáveis. Por exemplo, não existem diferenças significantes entre brancos e negros, homens e mulheres, no tempo transcorrido entre a solicitação e a cirurgia. Isto é observado para todos os grupos de idade, níveis educacionais, estados conjugais, rendimento per capita, religião e número de filhos nascidos vivos.

Apesar de não haver diferenças estatisticamente significantes entre homens e mulheres 
(no nível de $61,0 \%$ de confidência pelo Teste de Wilcoxon e $45,0 \%$ pelo Teste do Log-Rank) no tempo médio para obter esterilização, há nuances interessantes para serem observadas no comportamento destes dois grupos, mostrados no Figura 1a. Embora os homens mostrem maiores probabilidades de conseguir esterilização no tempo transcorrido entre a solicitação e a realização da cirurgia, não há maiores variações quando comparadas às probabilidades para as mulheres, com exceção dos sessenta dias iniciais. No primeiro mês, a probabilidade de homens e mulheres se esterilizarem é exatamente a mesma, enquanto que no segundo, as mulheres não conseguem nenhuma esterilização, mas os homens começam a conseguir a vasectomia. Este fato pode estar ilustrando que a lei não tem sido estritamente seguida para todos os usuários e que não se aplica tão estritamente aos homens como para as mulheres.

O tipo de serviço de saúde foi a única variável, dentre as testadas, que mostrou grande e significante diferença no tempo de espera para conseguir a esterilização (no nível de 99,0\% de confidência pelo Teste de Wilcoxon e 95,0\% pelo Teste do Log-Rank). A Figura 1b mostra que os usuários dos serviços hospitalares ambulatoriais esperaram muito menos tempo para conseguir a esterilização do que aqueles que procuraram um centro de saúde localizado longe de um hospital. Usuários de ambos os tipos de estabelecimentos de saúde foram esterilizados antes dos sessenta dias de carência entre o pedido e a cirurgia, mas as probabilidades de isto acontecer são maiores nos centros de saúde de hospitais. Como mencionado no início do trabalho, o SUS em algumas cidades ainda não está organizado na área de saúde reprodutiva, portanto, é mais provável que as esterilizações realizadas dentro dos sessenta dias tenham ocorrido nestas cidades. A probabilidade de sucesso em conseguir a esterilização é também bem maior nos centros de saúde de hospitais. Este fato pode colocar em grande desvantagem comparativa as pessoas que moram em municípios onde não há hospital.

Finalmente, observa-se uma diferença importante quando se analisa, separadamente para mulheres e homens, o tempo de espera para esterilização, segundo os dois tipos de estabelecimentos de saúde (Figura 2). O modelo para mulheres mostra diferença estatística significante (no nível de 98,0\% de confidência pelo Teste de Wilcoxon e 94,0\% pelo Teste do LogRank) entre os dois tipos de serviços de saúde, com maiores chances se a via foi ambulatórios de hospitais. A esterilização de homens não mostra diferenças estatísticas significantes, possivelmente porque a vasectomia é um procedimento médico mais simples e pode ser realizado em centros de saúde menos equipados. Este resultado indica, mais uma vez, que existem importantes fatores relacionados a diferenças de gênero com relação à esterilização voluntária que devem ser tomadas em consideração no momento da organização do sistema de saúde, se melhor qualidade e acesso aos serviços devem ser fornecidos indiscriminadamente a todos os usuários.

\section{Observações finais}

Os dados já amplamente conhecidos no país referentes à prevalência da laqueadura tubária e da vasectomia são eloqüentes quanto ao papel que tem cabido às mulheres, em especial às unidas, no sentido da regulação da fecundidade e do controle definitivo da reprodução.

Os últimos dados nacionais disponíveis (PNDS-1996), mostram que dos homens casados ou unidos, apenas $2,4 \%$ estavam vasectomizados, enquanto que $40,3 \%$ tinham esposas já esterilizadas. Informa ainda que a esterilização feminina era mais conhecida pelos homens $(87,7 \%)$ do que a própria vasectomia $(72,3 \%)$

Embora menos freqüente e proibida como prática de esterilização antes de 1997, a vasectomia já figurava como um procedimento pago pelo SUS desde 1992. O simples fato da existência do código para vasectomia antes de 1997 indica as contradições do sistema de saúde, o qual pagava pela vasectomia e não pela laqueadura tubária mesmo antes da legalização.

Para a realização no SUS da laqueadura tubária, as mulheres ou se submetiam a cesáreas desnecessárias ou tinham este procedimento cirúrgico registrado sob o código de salpingectomia.

Em que pese o fato de que em ambos os casos estes procedimentos poderiam ser recomendados para outros propósitos e não como forma de esterilização, não se tem elementos para afirmar em que proporção estes casos foram usados como forma de escamotear a realidade e burlar a legislação então vigente.

A Portaria 144 veio normatizar, no país, a prática da esterilização voluntária de homens e mulheres, legitimando-a no repertório dos direitos reprodutivos.

O presente estudo refere-se aos resultados de uma pesquisa conduzida dois anos após a publicação da Portaria 144.

No que se refere aos profissionais responsáveis pela saúde reprodutiva - gestores esta- 
Figura 1

Probabilidade de obter esterilização voluntária no SUS durante acompanhamento de aproximadamente seis meses, segundo o sexo dos usuários ou tipos de estabelecimento de saúde.

Figura 1a

Por sexo.

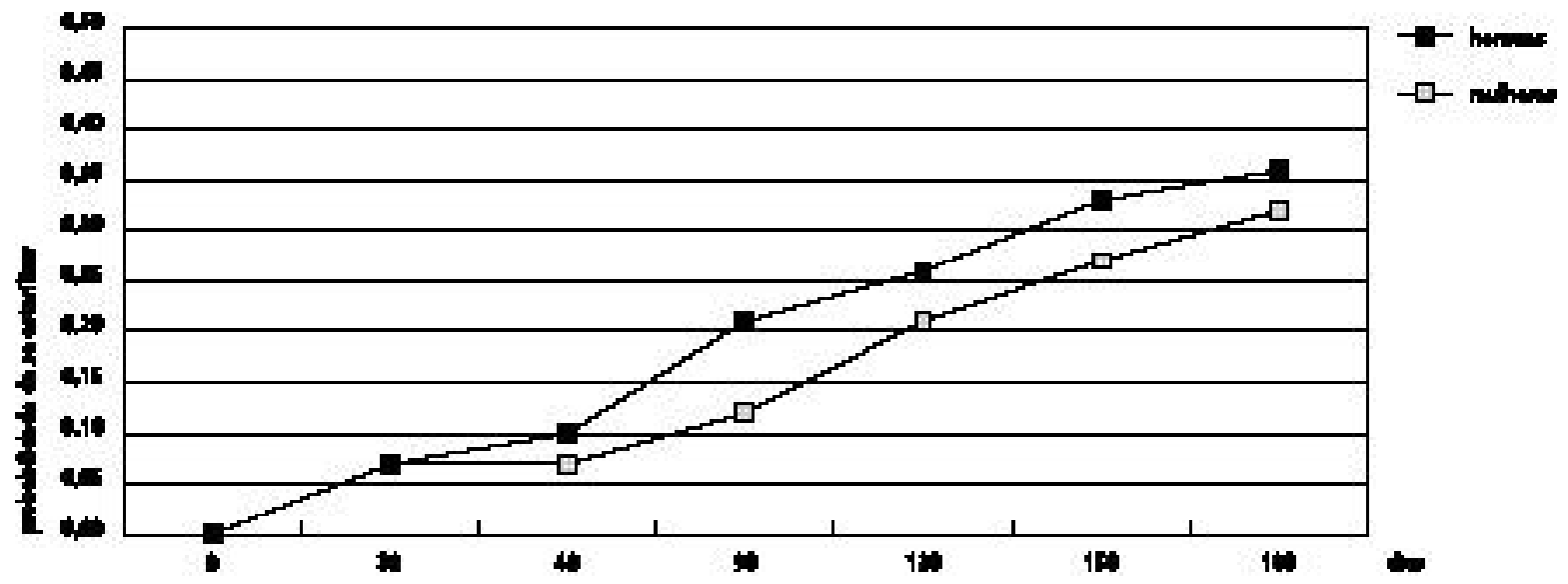

Figura 1b

Por tipo de estabelecimento.

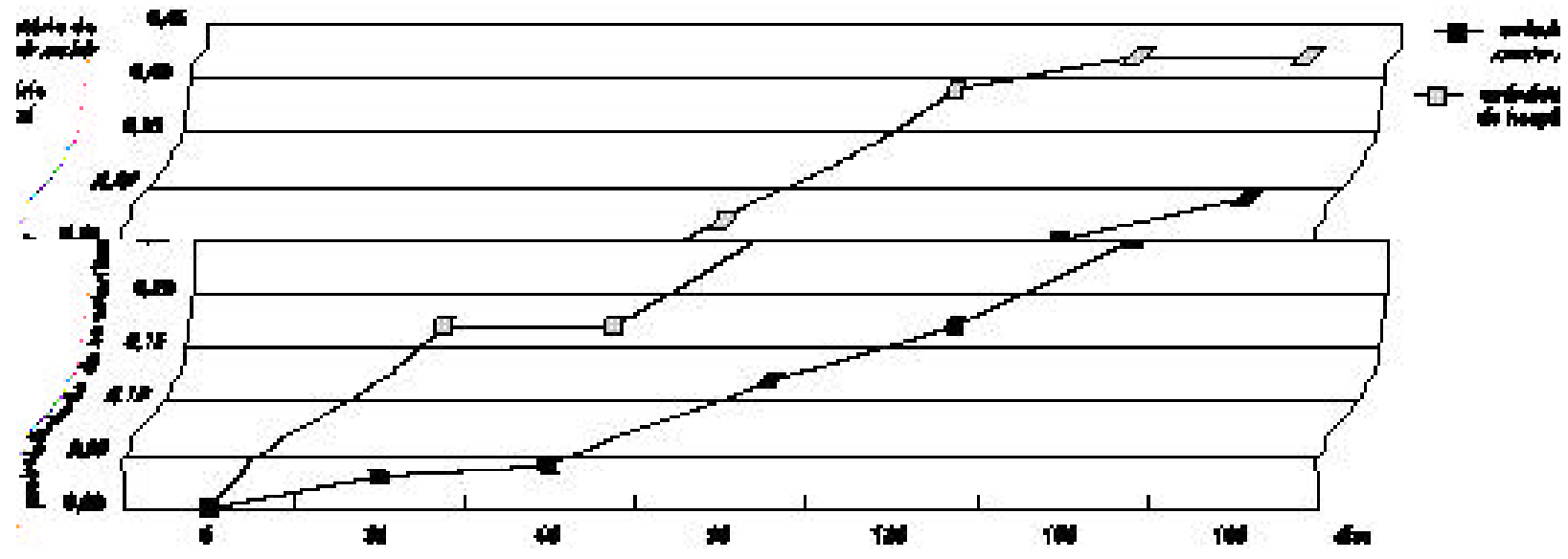


Figura 2

Probabilidade de obter laqueadura tubária ou vasectomia no SUS durante acompanhamento

de aproximadamente seis meses, segundo os tipos de estabelecimento de saúde.

Figura 2a

Laqueadura tubária.

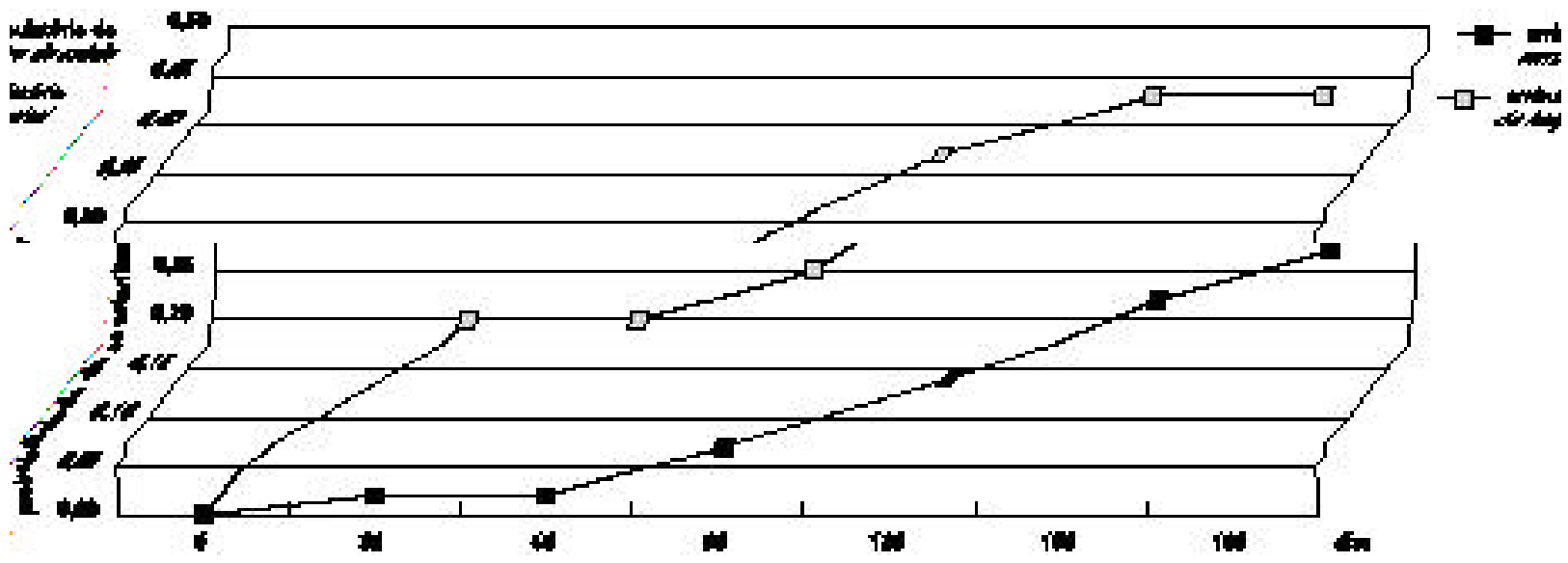

Figura $2 b$

Vasectomia.

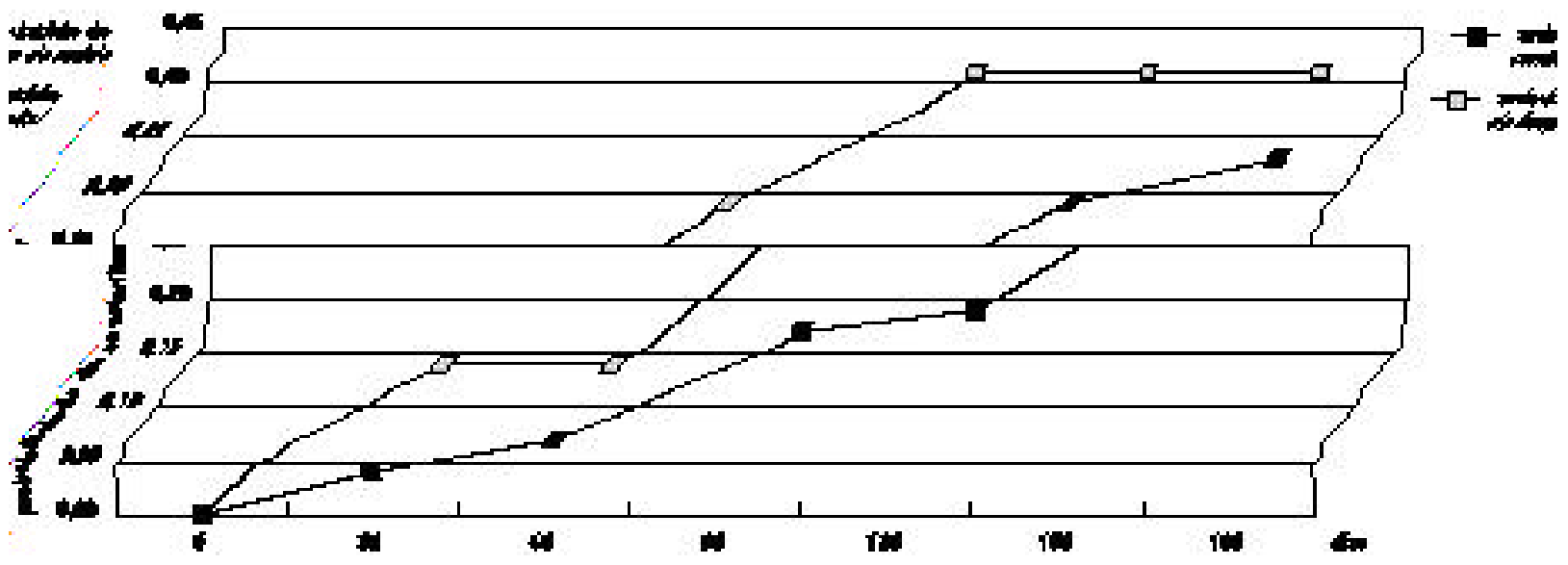


duais e municipais e diretores de hospitais e de ambulatórios - os achados revelam a necessidade de ações mais específicas e concretas do MS no sentido de ampla divulgação de novas legislações, portarias e normas, uma vez que, em alguns contextos, se quer a portaria em causa era conhecida no setor de saúde. Cabe a mesma observação quanto à responsabilidade dos órgãos estaduais com relação aos municipais. O monitoramento da aplicação de portarias e normas, via mecanismos de controle social, por exemplo, conselhos estaduais e municipais de saúde, poderá contribuir para a redução do grau de arbitrariedade dos profissionais de saúde reprodutiva na observância e extrapolação dos requisitos básicos para uma esterilização cirúrgica. O fato de estados e municípios terem limites anuais (financeiros e numéricos) de internação pelo SUS, e dos leitos para esterilização competirem com outras necessidades de saúde, são fatores a ser também considerados na análise do tempo de espera para uma esterilização. Os elementos aqui elencados ajudam a esclarecer as baixas proporções de esterilizações realizadas após seis meses de acompanhamento de homens e mulheres. Ajudam a compreender também o elevado índice de pessoas que não tendo conseguido a cirurgia alegaram que o SUS não respeita a lei e todo o processo é caracterizado por alta burocracia. Vale salientar, entretanto, que a porta de entrada no sistema de saúde mostrou-se elemento importante na implementação das cirurgias. Os ambulatórios de hospitais, especialmente no caso das mulheres, reduzem as dificuldades burocráticas e agilizam o acesso às ligaduras tubárias.

Sobre as pessoas que se apresentaram para solicitar a esterilização, valem algumas observações. A primeira é que nenhuma delas estava fora dos limites de idade ou de número de filhos permitidos pela nova legislação. Este resultado pode ter duas interpretações, ambas positivas, a saber: os requisitos expressos na portaria correspondiam ao perfil da demanda, e os solicitantes tiveram acesso prévio aos termos da portaria. A segunda diz respeito à eventual elevação da exposição das pessoas a uma gravidez não desejada, em função de um longo tempo de espera. Dentre os entrevistados, $23,9 \%$ das mulheres e $39,5 \%$ dos homens declararam não estar usando nenhum meio anticoncepcional no momento da pesquisa e $8,0 \%$ das mulheres engravidaram durante o período da espera. Finalmente, o aconselhamento colocado na portaria como requisito prévio à decisão por uma esterilização, envolvendo explicações sobre todos os métodos anticoncepcionais reversíveis, deveria ser repetido após uma esterilização, para enfatizar a importância do sexo seguro para evitar DST/AIDS.

\section{Agradecimento}

Pelo amplo apoio da Fundação Ford que financiou inteiramente o projeto que deu origem a este trabalho, nossos agradecimentos. Agradecemos especialmente a colaboração das coordenadoras locais do projeto: Osmaildes Lacerda Pedreira, da Associação Brasileira de Enfermagem de Tocantins; Maria Betânea Ávila, da ONG "SOS Corpo - Gênero e Cidadania" de Recife, Pernambuco; Mônica Baramaia, da ONG "Mulher e Saúde - Centro de Referência de Educação em Saúde da Mulher" de Belo Horizonte, Minas Gerais; Olinda do Carmo Luiz, da ONG "Comissão de Cidadania e Reprodução” de São Paulo; Vânia Muniz Nequer Soares, da Associação Brasileira de Enfermagem do Paraná e da Associação Brasileira de Obstetrícia e Enfermeiras Obstétricas do Paraná e Wilza Rocha Pereira, da Associação Brasileira de Enfermagem de Mato Grosso. 


\section{Referências}

BARROS, F. C.; VAUGHAN, J. P.; VICTORA, C. G. \& HUTTLY, S. R. A., 1991. Epidemic of caesarean section in Brazil. Lancet, 38:167-169.

BERQUÓ, E., 1993. Brasil, um caso exemplar, anticoncepção e partos cirúrgicos, à espera de uma ação exemplar. Estudos Feministas, 1:366-381.

BRASIL, 1997a. Lei ordinária 9.263, de 12 de janeiro de 1996. Regula o parágrafo 7 do artigo 226 da Constituição Federal, que trata do planejamento familiar, estabelece penalidades e dá outras providências. Diário Oficial da União, 20 ago.

BRASIL, 1997b. Portaria 144, de 20 novembro, 1997. Diário Oficial da União, 24 nov.

CAETANO, A. J., 2000. Sterilization for Votes in the Brazilian Northeast: The Case of Pernambuco. Ph.D. Thesis, Austin: University of Texas at Austin.

CFM (Conselho Federal de Medicina), 1984. Código Brasileiro de Deontologia Médica, Resolução CFM N. 1.154 de 13/04/84. Brasília: CFM.

DATASUS (Departamento de Informática do SUS), 2001. Assistência à Saúde: Procedimentos Hospitalares por Local de Internação. Março $2001<\mathrm{http}$ : //www.datasus.gov.br>.

FAÚNDES, A. \& CECATTI, J. G., 1991. A operação cesárea no Brasil: Incidência, tendências, causas, conseqüências e propostas de ação. Cadernos de Saúde Pública, 7:150-173.
FAÚNDES, A. \& CECATTI, J. G., 1993. Which policy for caesarian sections in Brazil? An analysis of trends and consequences. Health Policy and Planning, 8:33-42.

HARDY, E.; BAHAMONDES, L.; OSIS, M. J.; COSTA, R. G. \& FAÚNDES, A., 1996. Risk factors for tubal sterilization. Regret, detectable before surgery. Contraception, 54:159-162.

HOPKINS, K. L., 1998. Under the Knife: Cesarean Section and Female Sterilization in Brazil. Ph.D. Thesis, Austin: University of Texas at Austin.

BEMFAM (Sociedade Civil Bem-Estar Familiar no Brasil)/MACRO INTERNATIONAL, 1997. Pesquisa Nacional sobre Demografia e Saúde. Rio de Janeiro: BEMFAM/Macro International.

SOUZA, M. R., 2001. Uma Contribuição ao Debate sobre Partos Cesáreos: Estudo Prospectivo no Município de São Paulo. Tese de Doutorado, Campinas: Universidade Estadual de Campinas.

VIEIRA, E. M. \& FORD, N. J., 1996. Regret after female sterilization among low-income women in São Paulo, Brazil. Family Planning Perspectives, 22: 32-37.

Recebido em 2 de setembro de 2003

Versão final reapresentada em 16 de dezembro 2003 Aprovado em 22 de dezembro de 2003 